\title{
Exercício de força ativa a via AKT/mTor pelo receptor de angiotensina II tipo I no músculo cardíaco de ratos
}

CDD. 20.ed. 796.022



\section{Resumo}

0 receptor de angiotensina II tipo I (AT1) tem uma importante participação no desenvolvimento da hipertrofia cardiaca. Em um trabalho publicado anteriormente, por nosso grupo, demonstramos que 0 bloqueio do receptor AT1 durante o treinamento de força inibiu a hipertrofia cardiaca em ratos. Por isso, o objetivo deste trabalho foi estudar a participação do receptor AT1 na ativação de vias de sinalização intracelular relacionadas com o aumento da síntese de proteína em ratos submetidos a uma sessão de exercício de força. Para isso, realizamos um experimento com seis grupos de animais ( $n=6$; cada): controle (Con), exercitado e sacrificado cinco minutos após o exercício (Exe 5), exercitado e sacrificado 30 minutos após o exercício (Exe 30), controle tratado com losartan (Con Los), tratado com losartan, exercitado e sacrificado cinco minutos após o exercício (Exe 5 Los), tratado com losartan, exercitado e sacrificado 30 minutos após o exercício (Exe 30 Los). Os resultados mostram que no grupo Exe 5 e Exe 30 ocorreu um aumento de $63 \%(P<0,05)$ e $62 \%(P<0,05)$, respectivamente, na fosforilação da proteína AKT comparado com o grupo controle. Enquanto a fosforilação da mTor foi aumentada $65 \%(\mathrm{P}<$ $0,05)$ somente no grupo Exe 30 comparado com o grupo controle, sendo estes efeitos bloqueados pelo uso do losartan nos grupos Exe 5 Los e Exe 30 Los. Portanto, esses resultados, juntamente com nossos resultados prévios, demonstram que o receptor AT1 tem participação na ativação da AKT e mTOR após uma sessão de exercício de força.

UnITERMOS: Receptor AT1; Hipertrofia cardíaca; Exercício de força.

\section{Introdução}

A prática regular de exercícios físicos leva a uma série de adaptaçôes fisiológicas no organismo de forma gradual que variam conforme as características do treinamento. Dentre as adaptações estão as cardiovasculares, com especial destaque para a hipertrofia cardíaca $(\mathrm{HC})$ que ocorre frente a alterações hemodinâmicas, as quais modificam as condiçōes de sobrecarga cardíaca durante as sessões de treinamento físico (Morganroth, MAron, Henry \& Epstein, 1975). Essa HC decorrente do treinamento é uma resposta compensatória ao aumento da tensão na parede ventricular, resultando em hipertrofia dos cardiomiócitos a fim de normalizar a tensão sobre a parede do miocárdio (COLAN, 1997; URHAUSEN \& KINDERMANN, 1992).

Um dos pontos fundamentais a ser atingido para o desenvolvimento da hipertrofia dos cardiomiócitos é o balanço positivo entre a síntese e a degradação de proteínas sarcoméricas. Esses mecanismos se iniciam através de sinais bioquímicos que são mediados por receptores, canais iônicos ou por proteínas ancoradas as membranas, como as integrinas (Russell, CuRtis, Koshman \& Samarel, 2010). De forma geral, receptores do tipo tirosina quinase, como o receptor do fator de crescimento semelhante a insulina tipo 
I (RIGF-I) são associados com a HC fisiológica, enquanto receptores acoplados a proteína $\mathrm{G}$, como o receptor de angiotensina II tipo I (ATI) estão relacionados com a hipertrofia patológica (CLERK, CUlLINGFord, Fuller, Giraldo, Markou, PikKarainen \& Sugden, 2007; McMullen \& Jennings, 2007).

Vários estudos tem sido conduzidos utilizando o treinamento físico aeróbico para mostrar a importância da via do receptor de tirosina quinase, o qual leva a ativação da via PI3K-Akt-mTOR no desenvolvimento da $\mathrm{HC}$ fisiológica (DEBOsCH, Treskov, Lupu, Weinheimer, Kovacs, Courtois \& Muslin, 2006; Kemi, Ceci, Wisloff, Grimaldi, Gallo, Smith, Condorelli \& Ellingsen, 2008; McMullen, Shioi, Zhang, Tarnavski, Sherwood, Kang \& IzUmo, 2003), no entanto, ainda não se tem bem descrito os mecanismos de sinalização celular da HC induzida pelo treinamento de força.

\section{Métodos}

\section{Amostra}

Trinta e seis ratos Wistar (peso corporal entre 250 e $300 \mathrm{~g}$ ) foram aleatoriamente distribuídos em seis grupos: controle $(\mathrm{CO}, \mathrm{n}=6)$, controle losartan (CO Los, $n=6$ ), exercitado e sacrificado 5 min após o exercício (Exe $5, \mathrm{n}=6$ ), tratado com losartan, exercitado e sacrificado 5 min após o exercício (Exe 5 Los, $n=6$ ), exercitado e sacrificado 30 min após o exercício (Exe 30, n = 6), tratado com losartan, exercitado e sacrificado $30 \mathrm{~min}$ após o exercício (Exe 30 Los, $n=6$ ). O tratamento com losartan (20 mg. $\left.\mathrm{kg}^{-1}\right)$ começou uma semana antes do início do protocolo experimental. Foi usado uma dose que sabidamente bloqueia o receptor AT1, sem interferir na pressão arterial (LI, SHARIFFI \& ShIFFrin, 1997). Todos os animais foram alojados em gaiolas individuais, receberam água e ração própria "ad libitum", foram mantidos em ambiente com temperatura média de aproximadamente 25 ${ }^{\circ} \mathrm{C}$ e submetidos a um regime de 12 horas claro/ escuro, durante o período do experimento. Todos os protocolos utilizados neste estudo estavam de acordo com as diretrizes do Colégio Brasileiro de Experimentação Animal (COBEA) e foi aprovado
Com o intuito de abordar essa questão, desenvolvemos um aparato de treinamento de força para animais, baseado no modelo descrito por TAMAKI, UCHIYAMA e NAKANO (1992). Assim, conseguimos reproduzir, em ratos Wistar, adaptações crônicas similares às encontradas em seres humanos, tais como o aumento de força e HC fisiológica (BARAuna, Batista, Costa Rosa, Casarini, Krieger \& Oliveira, 2005; Barauna, Rosa, Irigoyen \& De Oliveira, 2007). Além disso, recentemente, em um estudo experimental com este modelo de treinamento de força, o bloqueio do receptor AT1 foi capaz de prevenir o desenvolvimento da HC, portanto sugerindo a participação do receptor AT1 na sinalização intracelular associada à HC fisiológica (Barauna, Magalhaes, Krieger \& Oliveira, 2008). Por isso, nosso objetivo foi verificar se este receptor ativa a via de sinalização intracelular AKT-mTOR na $\mathrm{HC}$ fisiológica, decorrente do treinamento de força.

pelo Comitê de Ética da Escola de Educação Física e Esporte da Universidade de São Paulo.

\section{Protocolo de exercício físico de força}

O exercício foi realizado com um modelo adaptado (TAMAKI, UChIYAMa \& NAKANO, 1992) e padronizado em nosso laboratório (BAURUNA et al., 2005). A adaptação foi realizada por quatro dias, 1x/dia, com carga de $200 \mathrm{~g}$ no primeiro dia, 300 $\mathrm{g}$ no segundo dia, $400 \mathrm{~g}$ no terceiro dia, um dia de recuperação entre o terceiro e o quarto dia e no último dia de adaptação a carga foi de $500 \mathrm{~g}$. Os animais foram colocados no sistema de treinamento e adaptados com quatro séries de 12 repetições com intervalo de 1 min e $30 \mathrm{~s}$. As patas posteriores dos animais são colocadas sobre uma placa de metal, a qual está conectada a um estimulador elétrico, assim o animal recebe um estímulo elétrico de $10-15 \mathrm{v}$, $0,3 \mathrm{~s}$ de duração, $4 \mathrm{~s}$ de intervalo. Este estímulo é de baixa intensidade e é usado para que o animal realize o exercício de agachamento. Este exercício de agachamento é muito semelhante ao realizado por humanos que fazem treinamento de força com levantamento de peso (FIGURA 1). 


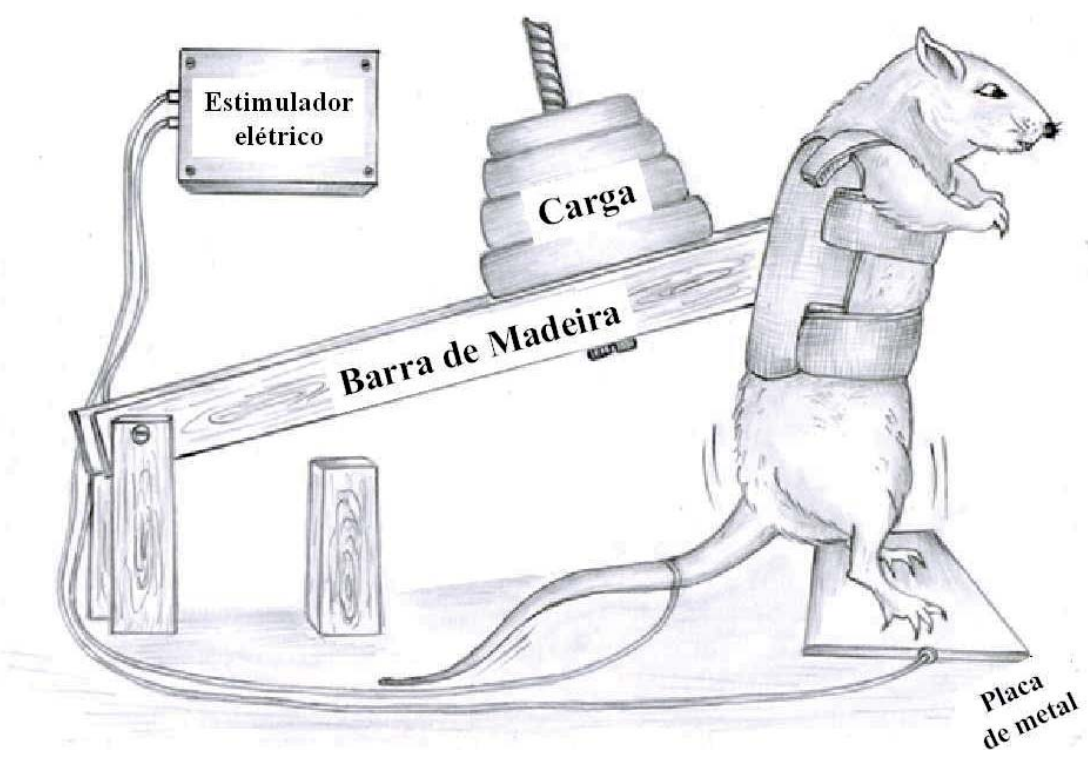

FIGURA 1 - Modelo do aparato de exercício de força.

No dia seguinte ao último dia de adaptação foi realizado o teste de $1 \mathrm{RM}$. O teste de $1 \mathrm{RM}$ é realizado da seguinte forma: É colocada uma anilha com 900 g (aproximadamente três vezes o peso corporal do animal) na barra de madeira do aparato de exercício de força. Em seguida o animal é estimulado a realizar o exercício. Após a realização do movimento um avaliador classifica o agachamento realizado pelo animal. Essa classificação permite ao avaliador aumentar ou diminuir o peso da barra em mais duas outras tentativas subsequentes até que se possa estipular na última tentativa o peso que o animal suporta levantar de maneira eficiente. Entre cada tentativa o animal permanece em recuperação durante cinco minutos (TAMAKI, UchiYAMa \& NAKANO, 1992).

Quarenta e oito horas após o teste os animais realizaram a sessão de exercício de força com sobrecarga de $80 \%$ de 1 RM (sendo a média de 1 RM dos grupos de $1215 \mathrm{~g} \pm$ 49) com quatro séries de 12 repetições e intervalo de 1 min e 30 s. Após a sessão, cada animal foi anestesiado com éter e decapitado, o coração do animal foi retirado e as câmaras separadas em ventrículo esquerdo (VE) e ventrículo direito (VD). OVD e $\mathrm{VE}$ foram pesados, porém somente o VE foi colocado em solução tampão, homogeneizado e adequadamente armazenadas em Freezer $\left(-20^{\circ} \mathrm{C}\right)$ para posterior análise.

\section{Análise da expressão protéica}

As amostras coletadas foram imediatamente homogeneizadas em tampão de extração contendo um coquetel de inibidores de proteases (Trisma base $100 \mathrm{mM}$, SDS $10 \%$, para-hidroximercuriobenzoato
(p-OHHgBz) $1 \mathrm{mM}$; fenilmetilsulfonilfluoreto (PMSF) $1 \mathrm{mM}$; pepstatina A $1 \mathrm{mM}$; orto-fenantrolina $30 \mathrm{mM}$ e ácido etilenodiamino tetra-acético (EDTA) $10 \mathrm{mM}$ ) e colocadas em banho a $100{ }^{\circ} \mathrm{C}$ por $10 \mathrm{~min}$. As amostras foram mantidas no gelo e centrifugadas (3.000 rpm x $10 \mathrm{~min}$ ) e mantidas a $-20{ }^{\circ} \mathrm{C}$. Os homogenatos foram centrifugados por $40 \mathrm{~min}$, a $12.000 \mathrm{rpm}$, a $4{ }^{\circ} \mathrm{C}$. O sobrenadante foi retirado, diluído em tampão Laemmli na proporção de 1:4 e aquecidos em água fervente por 5 min (LAEMMLI, 1970). Posteriormente foram submetidos à eletroforese em gel de poliacrilamida (SDS-PAGE 8\%) no aparelho para minigel (MiniProtean). A transferência das proteínas separadas no gel foi feita eletricamente para uma membrana de nitrocelulose utilizando-se um aparelho da Bio-Rad por aproximadamente $2 \mathrm{~h}$ sob 120 volts (Towbin, Ozbey \& Zingel, 2001). As membranas foram bloqueadas pela incubação com $10 \mathrm{ml}$ de solução bloqueadora a $4{ }^{\circ} \mathrm{C}$ overnight ou por $2 \mathrm{~h}$ na temperatura ambiente. As membranas foram posteriormente incubadas a $4{ }^{\circ} \mathrm{C}$ com o anticorpos para AKT $\left(\operatorname{ser}^{473}\right)$ total e AKT $\left(\operatorname{ser}^{473}\right)$ fosforilada, mTOR total e mTOR fosforilada (abcam,1:1000) e GAPDH (abcam, 1:2000) diluídos em solução bloqueadora (leite desnatado Molico 3\%, Tris 10mM, NaCl $150 \mathrm{mM}$ e Tween 20 0,02\%). O nível de expressão do GAPDH foi utilizado para normalizar os resultados. As membranas foram lavadas três vezes por 10 minutos com solução basal. As bandas existentes nas membranas incubadas foram visualizadas através do uso do kit para detecção por quimioluminescência. $\mathrm{O}$ método de 
quimioluminescência consiste nos seguintes passos: após incubação da membrana com o anticorpo primário, a membrana foi novamente incubada por $1 \mathrm{~h}$ com o anticorpo secundário anti-"rabbit" marcado com "horseradish peroxidase" em solução bloqueadora (1:2000). Em seguida as membranas foram lavadas novamente três vezes com solução basal e incubadas com $1 \mathrm{ml}$ de cada um dos dois reagentes do kit por um minuto, e a seguir os filmes de raio- $\mathrm{x}$ foram expostos às membranas. A exposição ao filme pode durar entre 30 segundos e dois minutos. Para se medir a intensidade das bandas nas auto-radiografias, as figuras escaneadas foram analisadas utilizando o

\section{Resultados}

Peso Corporal - a TABELA 1 mostra o peso corporal dos animais. Não houve diferença no peso corporal entre os grupos.

Repetição Máxima - pode-se observar que todos os grupos iniciaram o protocolo com 1 RM com cargas semelhantes (TABELA 1). Analisando a carga de 1 RM normalizados programa de análise de densitometria óptica Scion Image, fornecido gratuitamente pela NIH (USA) via internet.( http://www.scioncorp.com/).

\section{Análise estatística}

A comparação entre os grupos foi feita pela ANOVA two-way. O teste de "pos hoc" de Duncan foi usado para comparação entre as medias, quando foram observadas mudanças significantes com ANOVA. Foi adotado para todos os experimentos um $\mathrm{p} \leq 0,05$ de significância. Todos os resultados estão apresentados na forma de média \pm desvio padrão.
Dados estão expressos como média \pm desvio padrão, com seis animais em cada grupo.

1 RM: uma repetição máxima;

VE: ventrículo esquerdo; PC: peso corporal;

Con: controle;

Exe 5: exercitado e sacrificado cinco minutos após o exercício;

Exe 30: exercitado e sacrificado 30 minutos após o exercício; Con Los: controle losartan; Exe 5 Los: tratado com losartan, exercitado e sacrificado cinco minutos após o exercício; Exe 30 Los: tratado com losartan, exercitado e sacrificado 30 minutos após o exercício.

TABELA 1 - Peso corporal, relação peso do ventrículo esquerdo/ peso corporal, uma repetição máxima absoluta e relativa.

\begin{tabular}{lcccccc}
\hline & Con & Con Los & Exe 5 & Exe 5 Los & Exe 30 & Exe 30 Los \\
\hline PC (g) & $273,3 \pm 3,1$ & $275,1 \pm 4,5$ & $275,3 \pm 3,6$ & $272,6 \pm 4,9$ & $274,3 \pm 3,6$ & $277,3 \pm 3,9$ \\
VE/PC(mg/g) & $2,04 \pm 0,02$ & $2,05 \pm 0,04$ & $2,04 \pm 0,03$ & $2,06 \pm 0,05$ & $2,05 \pm 0,04$ & $2,03 \pm 0,03$ \\
$\mathbf{1 R M}(\mathbf{g})$ & $1212,5 \pm 46$ & $1208,3 \pm 51$ & $1216,6 \pm 66$ & $1225 \pm 44$ & $1220,3 \pm 60$ & $1208,3 \pm 43$ \\
\hline $\mathbf{1 R M} / \mathbf{P C}(\mathbf{g} / \mathbf{g})$ & $4,4 \pm 0,1$ & $4,39 \pm 0,16$ & $4,41 \pm 0,21$ & $4,49 \pm 0,17$ & $4,44 \pm 0,20$ & $4,35 \pm 0,16$ \\
\hline
\end{tabular}

A FIGURA 2 demonstra o resultado da fosforilação da proteína $\mathrm{AKT}\left(\mathrm{Ser}^{473}\right)$ e mTor no ventrículo esquerdo de ratos. No grupo Exe 5 e Exe 30 houve um aumento de $62,6 \%$ e $62,4 \%$ na fosforilação da proteína AKT, quando comparado ao grupo controle, respectivamente, sendo este efeito bloqueado pelo losartan no grupo Exe 5 Los $(60,6 \%)$ e Exe 30 Los $(78,5 \%)$. Estes resultados demonstram que o receptor AT1 desempenha uma importante função na pelo peso corporal, verificou-se que os animais levantaram uma carga de cerca de três vezes do peso corporal e também não foi verificado diferença entre os grupos.

Índice de Hipertrofia Cardíaca - não foi observado alteração na relação do peso do ventrículo esquerdo e peso corporal entre os grupos. ativação da AKT após uma sessão de exercício de força (FIGURA 2 A-B, $\mathrm{P}<0,05)$. A proteína $\mathrm{mTOR}$, alvo de fosforilação da proteína AKT aumentou 64,5\%, somente no grupo Exe 30, quando comparado com o grupo controle (FIGURA 3 A-B, P < 0,05), sendo observada uma diferença na fosforilação da mTOR entre o grupo Exe 30 e o grupo Exe 30 Los $(67,8 \%)$, indicando que o receptor AT1 participa da ativação da $\mathrm{AKT} / \mathrm{mTOR}$ após uma sessão de exercício de força. 
2A

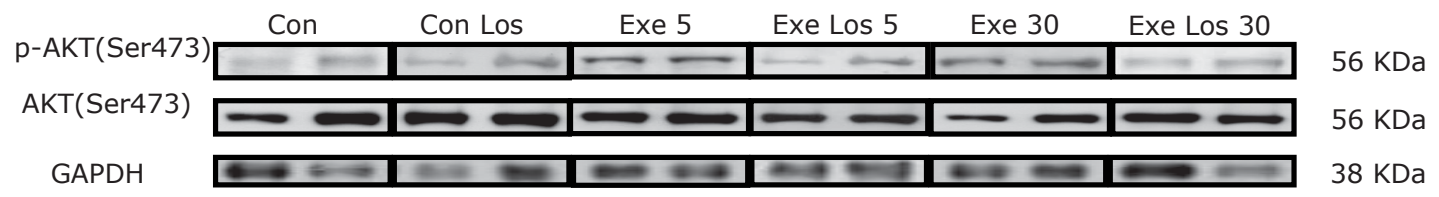

FIGURA 2:

B: Efeito de uma sessão de exercício de força na fosforilaçaõ da AKT $\left(\mathrm{Ser}^{473}\right)$ no VE (nor-

2B

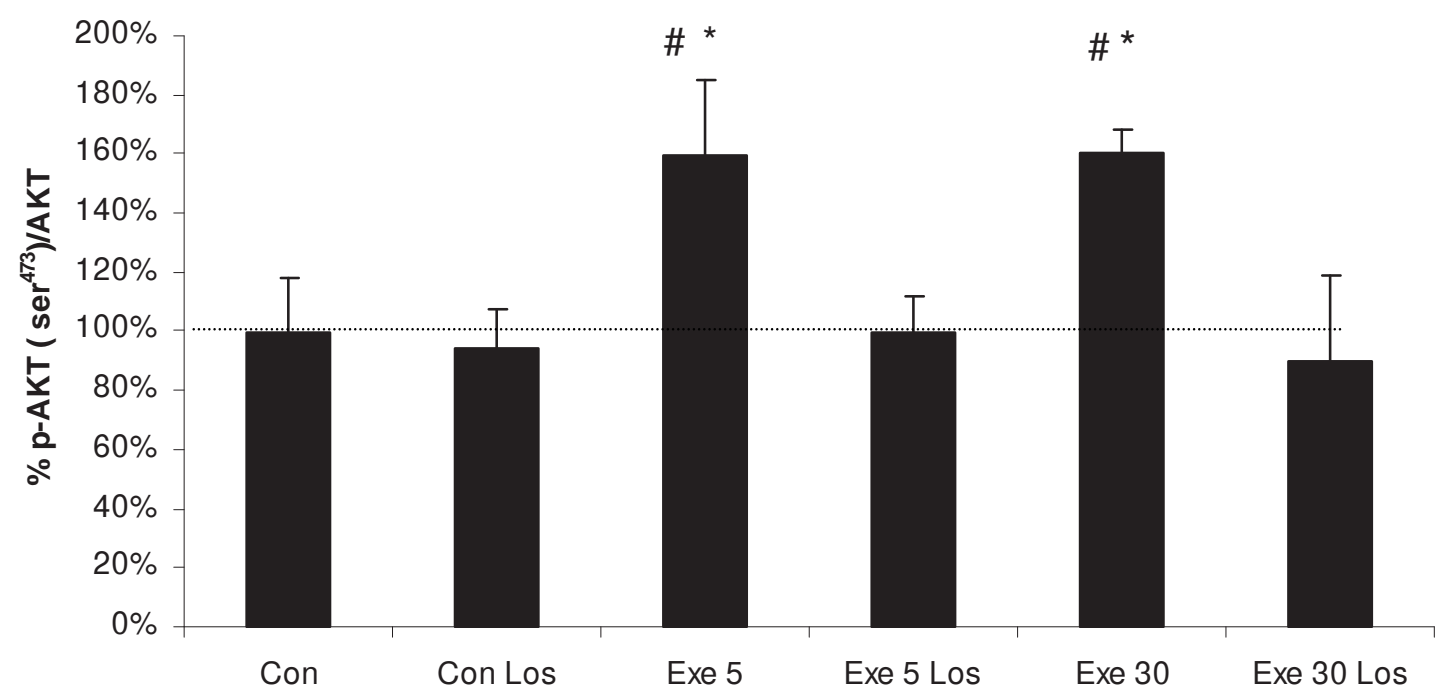

FIGURA 2 - Fosforilação da proteína AKT.

malizados pela proteína GAPDH).

FIGURAS 2 e 3 :

A: Bandas representativas do Western Blot das proteínas totais e fosforilada;

Con: controle;

Exe 5: exercitado e sacrificado cinco minutos após o exercício;

Exe 30: exercitado e sacrificado 30 minutos após o exercício; con Los: controle losartan; Exe 5 Los: tratado com losartan, exercitado e sacrificado cinco minutos após o exercício; Exe 30 Los: tratado com losartan, exercitado e sacrificado 30 minutos após 0 exercício:

Dados estão expressos como média \pm desvio padrão, com seis animais em cada grupo; ${ }^{*} P<0,05$ vs. grupos cont ou cont los; $\# P<0,05$ vs. grupos Exe 5 ou Exe 30 Los.

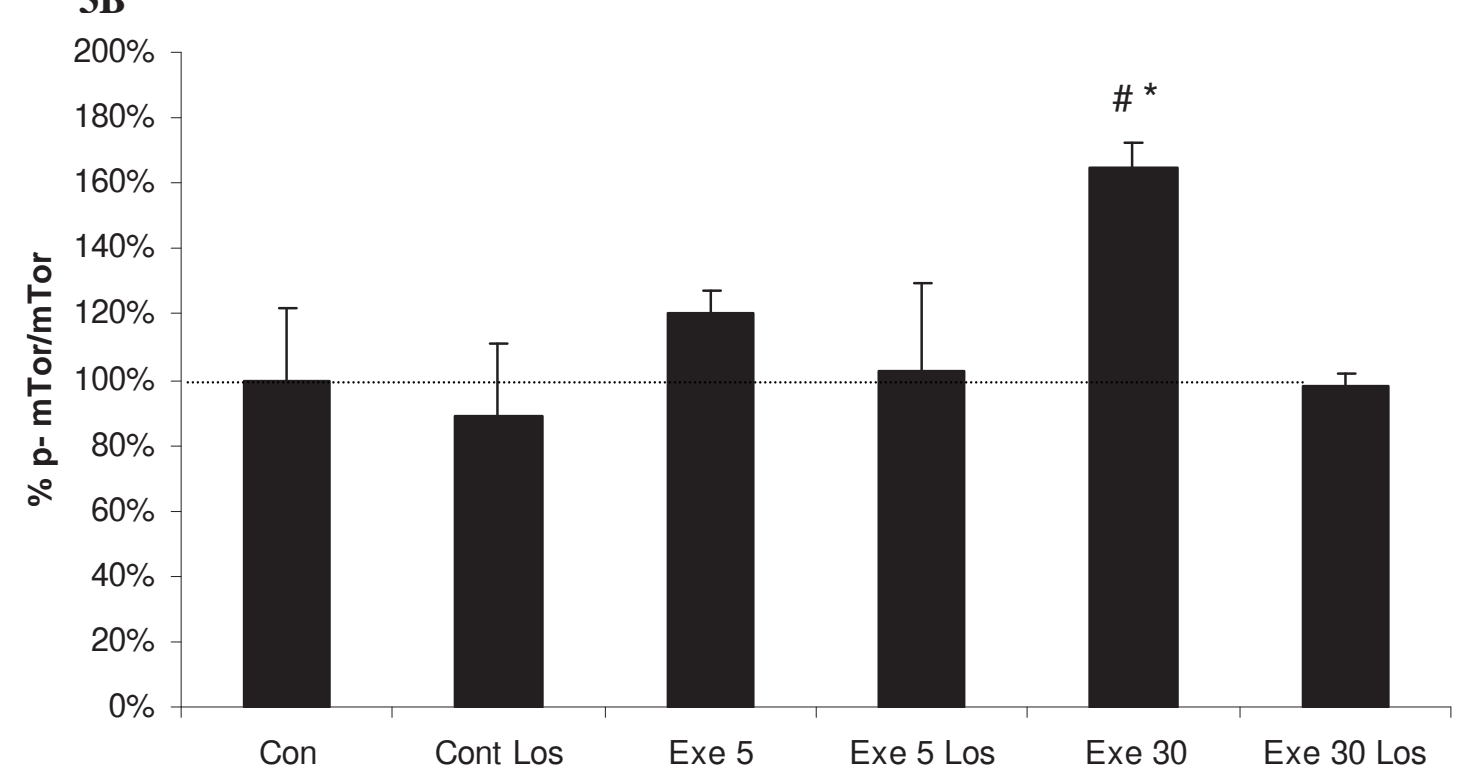

FIGURA 3:

B: Efeito de uma sessão de exercício de força na fosforilaçaõ da mTor no VE (normalizados pela proteína GAPDH).

FIGURA 3 - Fosforilação da proteína mTor. 


\section{Discussão}

Nesse estudo, mostramos a participação do receptor AT1, na sinalização intracelular induzida por uma sessão de exercício de força através do bloqueio com losartan. Ainda demonstramos que uma sessão de exercício de força foi capaz de induzir a ativação da via de sinalização intracelular AKT-mTOR no VE de ratos dependente da ativação do receptor AT1.

Anteriormente, usando este modelo de treinamento de força nosso grupo já havia mostrado o desenvolvimento de hipertrofia fisiológica concêntrica e diminuição da pressão arterial diastólica e média de repouso (BARAÚNA et al., 2007). Em trabalhos prévios, também demonstramos que neste modelo de treinamento de força, ocorre o desenvolvimento da HC fisiológica concêntrica, sem disfunção ou redução da cavidade ventricular, sendo que essas alterações ocorreram sem alteração na função ventricular (BARAUNA et al., 2007). Estes resultados, corroboram com resultados observados em atletas que realizam treinamento de força (Sun, MA, Yong \& Lv 2007; Whyte, George, Sharma, Firoozi, Stephens, Senior \& McKenna, 2004). Além disso, demonstramos que o receptor AT1 participa do desenvolvimento da $\mathrm{HC}$ sem alterar a expressão gênica da relação alfa/beta MCP (miosina de cadeia pesada) e ANF, os quais são dois importantes marcadores de hipertrofia cardíaca patológica (BArauna et al., 2008). Desta forma, demonstramos que a $\mathrm{HC}$ concêntrica resultante do treinamento de força, no modelo estudado, não apresenta características patológicas.

A participação do receptor AT1 no desenvolvimento da HC, pelo treinamento de força, ocorreu sem alteração na concentração da Ang II cardíaca e circulante, na atividade da enzima conversora de angiotensina I, da renina plasmática e com diminuição da expressão do angiotensinogênio no coração, sugerindo que a participação deste receptor na ativação das vias intracelulares ocorre por estiramento mecânico (BARAUNA et al., 2008).

A presença da Ang II é um ponto que pode diferenciar a ativação das vias intracelulares através do receptor AT1. Enquanto, a Ang II tem se mostrado fundamental para ativar a via da proteína $G$ e promover o desenvolvimento de $\mathrm{HC}$ em modelos patológicos (WetTsChureck, RutTen, ZywieTZ, Gehring, Wilkie, Chen, Chien \& Offermanns, 2001), Zou, Akazawa, Qin, Sano, Takano, Minamino, Makita, Iwanaga, Zhu, Kudoh, ToKo, Tamura, Kihara, Nagai, Fukamizu, Umemura, Iiri, Fujita e Komuro (2004) verificaram que o receptor AT1 funciona como um sensor mecânico, ativando vias de sinalização hipertrófica, quando submetido ao estiramento mecânico em cultura de cardiomiócitos, na ausência da Ang II. Além disso, essa via de ativação acontece com menor participação na ativação da proteína $\mathrm{G}$ e com maior ativação da via Jak2. Interessantemente, FrANK, Kuhn, Brors, Hanselmann, Ludde, Katus e Frety (2008) verificaram que o receptor AT1 ativado por estiramento mecânico foi responsável pela ativação de genes envolvidos com cardioproteção em cultura de cardiomiócitos e que isso ocorreu, provavelmente pela capacidade do receptor AT1 ativar vias que independem da proteína $\mathrm{G}$.

Além do receptor AT1 outros receptores como o de IGF-1 também está envolvido com o aumento da síntese de proteína e hipertrofia dos cardiomiócitos. Estudos verificaram que níveis de IGF-1 estavam aumentados em atletas profissionais (NERI SERNERI, Boddi, Modesti, Cecioni, Coppo, Padeletti, Michelucci, Colella \& Galanti, 2001; Walsh, 2006) e ratos treinados (SCHEINOWITZ, KesSLER-ICEKSON, Freimann, Zimmermann, Schaper, Golomb, Savion $\&$ ELDAR, 2003). Esse aumento na produção de IGF1 cardíaco com o treinamento aeróbico está associado com o desenvolvimento da HC fisiológica. Animais nocaute para o receptor de IGF-1, quando submetidos ao treinamento de natação confirmaram a participação do receptor de IGF-1R na HC fisiológica (KeMI, CeCI, Wisloff, Grimaldi, Gallo, Smith, Condorelli \& ELLINGSEN, 2008). Essa ativação do receptor de IGF-1 também, está associada com a via da PI3K-AKTmTOR, como verificado nos trabalhos que utilizaram animais nocautes para a subunidade $\mathrm{p} 110$ alfa da PI $3 \mathrm{~K}$, ou então animais com inativação gênica para AKT, que não apresentavam $\mathrm{HC}$ quando submetidos ao treinamento aeróbico (DeBOsCh et al., 2006).

Embora, esta via tenha sido sugerida para induzir a HC fisiológica em animais após protocolo de treinamento de natação, esteira rolante com intensidade moderada ou protocolo de treinamento físico intervalado de alta intensidade (Deвosch et al., 2006; Kemi et al., 2008; McMullen, et al., 2003), um aumento inesperado foi verificado na fosforilação da AKT nos animais treinados com inativação do receptor de IGF-1R, o que sugere uma outra via de ativação para a AKT com o treinamento aeróbico, que não depende da via do receptor de IGF-1R.

As vias de sinalização intracelular ativadas com o treinamento de força ainda não tinham sido 
estudas, assim como os receptores responsáveis pela ativação das vias intracelulares. Desta forma, neste trabalho mostramos pela primeira vez, que o receptor AT1 está participando da ativação da AKT, com uma sessão aguda de exercício de força em modelo animal. Embora o receptor AT1 participe da ativação de vias de sinalização celular envolvida com o desenvolvimento da HC patológica (AKHTER, LutTrell, Rockman, Iaccarino, Lefkowitz \& Koch, 1998; Levy, Garrison, Savage, Kannel \& CASTELli, 1990), neste trabalho demonstramos que este receptor também ativa a via da AKT-mTOR, característica do desenvolvimento da HC fisiológica, como neste modelo de treinamento que utilizamos.

Diferentes trabalhos têm estudado a ativação das proteínas PI3K-AKT-mTOR, comparando modelo de sobrecarga de pressão através da constrição transversal da aorta, com o efeito do treinamento aeróbico em animais experimentais, o qual provoca uma sobrecarga de volume no coração (DEBOSCH et al., 2006; Kemi et al., 2008). Entretanto, entendemos que um modelo de treinamento de força capaz de promover uma sobrecarga de pressão fisiológica parece ser a melhor forma de comparação com a sobrecarga de pressão imposta por constrição transversal da aorta no coração, sendo, mais adequada para o estudo das sinalizaçôes responsáveis por adaptaçôes morfológicas características do estímulo pressórico, seja fisiológico ou patológico.

Os resultados obtidos neste estudo permitem concluir, que embora a $\mathrm{HC}$ seja concêntrica e induzida por sobrecarga pressórica, a qual é intermitente, ativa uma via de sinalização bem demonstrada para a $\mathrm{HC}$ fisiológica excêntrica, que é induzido pela sobrecarga de volume. Assim, neste estudo demonstramos que o treinamento de força que promove $\mathrm{HC}$ concêntrica está ativando a via de sinalização AKT-mTor via receptor AT1, após uma sessão de exercício de força.

\begin{abstract}
Activation of AKT-mTor signaling pathways by angiotensin II receptor type 1 after a session of strength exercise in cardiac muscle of rats

The angiotensin II type I (AT1) receptor has an important participation in the development of cardiac hypertrophy. Previously, we have shown that AT1 receptor participates in the cardiac hypertrophy induced by resistance training in rats. Here, we studied the involvement of AT1 receptor in the activation of intracellular signaling pathways related to the concentric $\mathrm{HC}$ in rats submitted to a session of strength exercise. Male Wistar rats were divided into 6 groups ( $n=6$ each): control (Con); exercised and killed 5 minutes after exercise (Exe 5); exercised and killed 30 minutes after exercise (Exe 30); control treated with Losartan (Con Los); treated with Losartan, exercised and killed 5 minutes after the exercise (Exe Los 5); treated with Losartan, exercised and killed 30 minutes after training (Exe Los 30$)$. The results show that phosphorylation activity of AKT in group Exe 5 and Exe 30 increased 63\% $(P<0.05)$ and 62\% $(\mathrm{P}$ $<0.05)$, respectively, compared with Con. Whereas the phosphorylation of mTOR was increased 65\% (P $<0.05$ ), compared to Con, only in the group Exe 30. Furthermore, these effects were blocked by losartan treatment in groups Exe Los 5 and Exe Los 30. These results, together with ours previous data shows that the AT1 receptor has an role in the activation of AKT and mTOR pathway after a session of strength exercise.
\end{abstract}

UnITERMS: AT1 receptor; Cardiac hypertrophy; Strength exercise.

\title{
Referências
}

AKHTER, S.A.; LUTTRELL, L.M.; ROCKMAN, H.A.; IACCARINO, G.; LEFKOWITZ, R.J.; KOCH, W.J. Targeting the receptor-Gq interface to inhibit in vivo pressure overload myocardial hypertrophy. Science, Washington, v.280, n.5363, p.574-7, 1998. BARAUNA, V.G.; BATISTA JUNIOR, M.L.; COSTA ROSA, L.F.; CASARINI, D.E.; KRIEGER, J.E.; OLIVEIRA, E.M. Cardiovascular adaptations in rats submitted to a resistance-training model. Clinical and Experimental Pharmacology and Physiology, Oxford, v.32, n.4, p.249-54, 2005. 
BARAUNA, V.G.; MAGALHAES, F. C.; KRIEGER, J.E.; OLIVEIRA, E.M. AT1 receptor participates in the cardiac hypertrophy induced by resistance training in rats. American Journal of Physiology: Regulatory Integrative and Comparative Physiology, Bethesda, v.295, n.2, p.381-7, 2008.

BARAUNA, V.G.; ROSA, K.T.; IRIGOYEN, M.C.; DE OLIVEIRA, E.M. Effects of resistance training on ventricular function and hypertrophy in a rat model. Clinical Medicine \& Research, Marshfield, v.5, n.2, p.114-20, 2007.

CLERK, A.; CULLINGFORD, T.E.; FULLER, S.J.; GIRALDO, A.; MARKOU, T.; PIKKARAINEN, S.; SUGDEN, P.H. Signaling pathways mediating cardiac myocyte gene expression in physiological and stress responses. Journal Cell Physiology, Philadelphia, v.212, n.2, p.311-22, 2007.

COLAN, S.D. Mechanics of left ventricular systolic and diastolic function in physiologic hypertrophy of the athlete's heart. Clinical Cardiology, Hoboken, v.15, n.3, p.355-72, 1997.

DEBOSCH, B.; TRESKOV, I.; LUPU, T.S.; WEINHEIMER, C.; KOVACS, A.; COURTOIS, M.; MUSLIN, A.J. Akt 1 is required for physiological cardiac growth. Circulation, Dallas, v.113, n.17, p.2097-104, 2006.

FRANK, D.; KUHN, C.; BRORS, B.; HANSELMANN, C.; LUDDE, M.; KATUS, H.A.; FREY, N. Gene expression pattern in biomechanically stretched cardiomyocytes: evidence for a stretch-specific gene program. Hypertension, Dallas, v.51, n.2, p.309-18, 2008.

KEMI, O.J.; CECI, M.; WISLOFF, U.; GRIMALDI, S.; GALLO, P.; SMITH, G.L.; CONDORELLI, G.; ELLING$\mathrm{SEN}, \mathrm{O}$. Activation or inactivation of cardiac Akt/mTOR signaling diverges physiological from pathological hypertrophy. Journal Cell Physiology, Philadelphia, v.214, n.2, p.316-21, 2008.

KIM, J.; WENDE, A.R.; SENA, S.; THEOBALD, H.A.; SOTO, J.; SLOAN, C.; WAYMENT, B.E.; LITWIN, S.E.; HOLZENBERGER, M.; LEROITH, D.; ABEL, E.D. Insulin-like growth factor I receptor signaling is required for exercise-induced cardiac hypertrophy. Molecular Endocrinology, Baltimore, v.22, n.11, p.2531-43, 2008.

LAEMMLI, U.K. Cleavage of structural proteins during the assembly of the head of bacteriophage T4. Nature, Basingstoke, v.227, n.5259, p.680-5, 1970.

LEVY, D.; GARRISON, R.J.; SAVAGE, D.D.; KANNEL, W.B.; CASTELLI, W.P. Prognostic implications of echocardiographically determined left ventricular mass in the Framingham Heart Study. The New England Journal Medicine, , v.322, n.22, p.1561-6, 1990.

LI, J.S.; SHARIFI, A.M.; SCHIFFRIN, E.L. Effect of AT1 angiotensin-receptor blockade on structure and function of small arteries in SHR. Journal of Cardiovascular Pharmacology, Hagerstown, v.30, n.1, p.75-83, 1997.

McMULLEN, J.R.; JENNINGS, G.L. Differences between pathological and physiological cardiac hypertrophy: novel therapeutic strategies to treat heart failure. Clinical and Experimental Pharmacology and Physiology, Oxford, v.34, n.4, p.255-62, 2007.

McMULlEN, J.R.; SHIOI, T.; ZHANG, L.; TARNAVSKI, O.; SHERWOOD, M.C.; KANG, P.M.; IZUMO, S. Phosphoinositide 3-kinase(p110alpha) plays a critical role for the induction of physiological, but not pathological, cardiac hypertrophy. Proceedings of the National Academy of Sciences of the United States of America, Washington, v.100, n.21, p.12355-60, 2003.

MORGANROTH, J.; MARON, B.J.; HENRY, W.L.; EPSTEIN, S.E. Comparative left ventricular dimensions in trained athletes. Annals of Internal Medicine, Philadelphia, v.82, n.4, p.521-4, 1975.

NERI SERNERI, G.G.; BODDI, M.; MODESTI, P.A.; CECIONI, I.; COPPO, M.; PADELETTI, L.; MICHELUCCI, A.; COLELLA, A.; GALANTI, G. Increased cardiac sympathetic activity and insulin-like growth factor-I formation are associated with physiological hypertrophy in athletes. Circulation Research, Baltimore, v.89, n.11, p.977-82, 2001. RUSSELL, B.; CURTIS, M.W.; KOSHMAN, Y.E.; SAMAREL, A.M. Mechanical stress-induced sarcomere assembly for cardiac muscle growth in length and width. Journal of Molecular and Cellular Cardiology, London, v.48, n.5, p.817-23, 2010.

SCHEINOWITZ, M.; KESSLER-ICEKSON, G.; FREIMANN, S.; ZIMMERMANN, R.; SCHAPER, W.; GOLOMB, E.; SAVION, N.; ELDAR, M. Short and long-term swimming exercise training increases mocardial insulin-like growth factor-I gene expression. Growth Hormone \& IGF Research, London, v.13, p.19-25, 2003.

SUN, B.; MA, J.Z.; YONG, Y.H.; LV, Y.Y. The upper limit of physiological cardiac hypertrophy in elite male and female athletes in China. European Journal Applied Physiology, Berlin, v.101, n.4, p.457-63, 2007.

TAMAKI, T.; UCHIYAMA, S.; NAKANO, S. A weight-lifting exercise model for inducing hypertrophy in the hindlimb muscles of rats. Medicine and Science in Sports and Exercise, Madison, v.24, n.8, p.881-6, 1992.

TOWBIN, H.; OZBEY, O.; ZINGEL, O. An immunoblotting method for high-resolution isoelectric focusing of protein isoforms on immobilized pH gradients. Electrophoresis, London, v.22, n.10, p.1887-93, 2001. 
URHAUSEN, A.; KINDERMANN, W. Echocardiographic findings in strength- and endurance-trained athletes. Sports Medicine, Auckland, v.13, n.4, p.270-84, 1992.

WALSH, K. Akt signaling and growth of the heart. Circulation, Dallas, v.113, n.17, p.2032-4, 2006.

WETTSCHURECK, N.; RUTTEN, H.; ZYWIETZ, A.; GEHRING, D.; WILKIE, T.M.; CHEN, J.; CHIEN, K. R.; OFFERMANNS, S. Absence of pressure overload induced myocardial hypertrophy after conditional inactivation of Galphaq/Galpha11 in cardiomyocytes. Nature Medicine, New York, v.7, n.11, p.1236-40, 2001.

WHYTE, G.P.; GEORGE, K.; SHARMA, S.; FIROOZI, S.; STEPHENS, N.; SENIOR, R.; McKENNA, W.J. The upper limit of physiological cardiac hypertrophy in elite male and female athletes: the British experience. European Journal Applied Physiology, Berlin, v.92, n.4-5, p.592-7, 2004.

ZOU, Y.; AKAZAWA, H.; QIN, Y.; SANO, M.; TAKANO, H.; MINAMINO, T.; MAKITA, N.; IWANAGA, K.; ZHU, W.; KUDOH, S.; TOKO, H.; TAMURA, K.; KIHARA, M.; NAGAI, T.; FUKAMIZU, A.; UMEMURA, S.; IIRI, T.; FUJITA, T.; KOMURO, I. Mechanical stress activates angiotensin II type 1 receptor without the involvement of angiotensin II. Nature Cell Biology, London, v.6, n.6, p.499-506, 2004.

\begin{tabular}{|c|c|}
\hline $\begin{array}{r}\text { ENDEREÇo } \\
\text { Stéphano Freitas Soares Melo } \\
\text { Escola de Educação Física e Esporte - USP } \\
\text { Av. Prof. Mello Moraes, } 65 \\
\text { 05508-030 - São Paulo - SP - BRASIL } \\
\text { e-mail: stephanomelo@usp.br }\end{array}$ & $\begin{array}{l}\text { Recebido para publicação: 17/ 05/ } 2010 \\
\text { 1a. Revisão: 03/ 11/ } 2010 \\
\text { 2a. Revisão: 16/ 05/2011 } \\
\text { Aceito: } 14 / 06 / 2011\end{array}$ \\
\hline
\end{tabular}

